\title{
Can Theism be Defeated?
}

For all of the reasons we have been discussing, god-bearing individuals usually find it extremely difficult to contest their religious credulity and conformity biases. This applies not only to laypeople, but to scholars who are affiliated with religious in-groups as well. Philosophy can help. It is no coincidence that the majority of professional philosophers embrace (or lean toward) atheism. Unfortunately, the road most travelled by unbelieving philosophers and scientists with a predilection for engaging the intellectual elite of culturally dominant monotheistic coalitions is marked by deep ruts carved out by centuries of debate over the same tired arguments for and against the probability (or possibility) of the existence of an omnipotent, omniscient, omnibenevolent God.

Occasionally one encounters theistic dialogue partners who are willing to budge a bit on issues like divine predestination or foreknowledge. When pressed on the coherence or plausibility of the very idea of a mysterious intentional force whose thoughts and desires (and even presence) can only be detected by in-group members ritually engaged in religious sects, however, progressive defenders of the faith make the same sort of predictable evasive hermeneutical maneuvers as their more traditionalist colleagues. How can we escape this disputatious cul-de-sac within which apologists and (too many) atheists have been circling for so long?

Instead of focusing primarily on the logical incoherence and empirical intractability of religious faith, which to many non-believers seem so obvious, I suggest we pay more attention to the way in which ritual interaction with imagined supernatural forces is engendered by an aggregate of evolved biases, to which many believers seem so oblivious. If we stay only at the level of explicit claims about gods (or God) we do not notice the implicit motivational reasoning that immunizes faith from critique and so easily activates believers' defensive reactions to (and even perceptions of) challenges to their supernatural beleifs and behaviors.

The apparent futility, monotony, and interminability of theoretical debates with religious apologists might lead us to conclude that an atheist's energy would be better spent identifying and implementing practical solutions to concrete problems. I'm all for the latter. ${ }^{1}$ However, one good reason for

1 See, e.g., the discussion of policy-oriented computer modeling and simulation methodologies at the end of Chapter 12 .

(C) F. LERON SHULTS, 2018 | DOI 10.1163/9789004360952_006

This is an open access chapter distributed under the terms of the CC BY-NC-ND 4.o license. Shults - 9789004360952 
staying engaged in a debate over the metaphysical implications of scientific discoveries about the mechanisms of religious reproduction is that the arguments of apologetic philosophers of religion and other religiously affiliated scholars can play an important role in reinforcing the attitudes and actions of religious laypeople, who are all too often resistant to any pragmatic solution that is forbidden (or not authorized) by the supernatural agents whom they think are watching over them.

On the one hand, many believers spend an inordinate amount of time imaginatively engaging secretive and punitive supernatural agents who supposedly have designs for redeeming those who are part of their religious alliance. On the other hand, they all too quickly become belligerent when confronted with the religious beliefs and behaviors of those allied with other supernatural coalitions, which they find rather decidedly bizarre. Atheists are often astonished that theists fail to notice this double standard. Perhaps even more surprising is the apparent lack of concern expressed by believers even after this partisan bias is pointed out. At least religious apologists are concerned enough to be defensive about it! As students of the history of philosophy and theology, they realize that the rise of scientific naturalism and the spread of pluralistic secularism present new and serious challenges to the credibility and cohesion of their religious coalitions.

Insofar as apologetic arguments provide cover for the flourishing of theistic credulity and conformity biases, thereby exacerbating the global tensions we all face, it is worthwhile to take the time (and space) to challenge them. Debunking the theological claims of their religious colleagues is one way that godless philosophers can promote an adaptive atheism. In this chapter, I briefly describe three steps that may help us break the bad habits that have for so long characterized discourse about the extent to which science, and especially the science of religion, debunks theism. These steps are woven into a conversation with a recent book by Helen De Cruz and Johan De Smedt titled A Natural History of Natural Theology: The Cognitive Science of Religion and Philosophy of Religion. $^{2}$

De Cruz and De Smedt have clearly demonstrated the extent to which - and the way in which - evolved cognitive tendencies play a role in the emergence of theistic ideas about God and in the formulation of theistic arguments meant to defend belief in his existence. Their contributions to the "naturalization"

2 De Cruz and De Smedt (Cambridge, MA: The mit Press, 2014). Unless otherwise noted, page numbers throughout this chapter refer to this book. An earlier version of this essay was originally published as a commentary on their book; see Shults, "Can Theism Be Defeated? csR and the Debunking of Supernatural Agent Abductions," Religion, Brain \& Behavior 6, no. 4 (2015). 
of theology and (theistic) philosophy of religion are a gift to the field. It is tempting to praise one chapter after another, but instead I will focus primarily on the one aspect of the book I found disappointing: their claim, stated early and often, but most forcefully in the final chapter, that the cognitive science of religion (CSR) "cannot straightforwardly provide a debunking account of natural theology and religion." The main warrant they offer for this claim is the difficulty they find "in choosing an appropriate level of explanation of how cognitive capacities generate religious beliefs" (179).

Their lack of confidence in the debunking force of empirical findings and theoretical developments in CSR and related disciplines may be due, in part, to the way in which they focus primarily on the content biases that generate ideas about gods (including God), and the relative lack of attention they give to the context biases that nurture them. This is why, in my view, their "naturalization" does not go far enough. The resilience of natural theology is indeed bolstered by the covert operation of hyper-sensitive cognitive biases that engender facile concepts of hidden, purposive agents. However, these god-conceptions only have staying power because of the facility of coalitional biases that reinforce shared imaginative engagement with such agents.

For the sake of this conversation, I accept their definition of theism as belief "in the existence of an omniscient, omnipresent, eternal morally perfect being who created the world and sustains its existence continuously" (xiii). I accept their definition of religions as "practices and beliefs that bind communities of people and that link them to a supernatural realm... features of human behavior that are regarded as religious (e.g., belief in supernatural beings, engaging in rituals) are present in all human cultures..." (12). And, finally, I accept their definition of debunking as the provision of arguments that "examine the causal history of a particular belief in a ways that undermines that belief" (2).

Can theism - and religious belief in supernatural agents in general - be debunked by philosophical reflection grounded in the findings of CSR? De Cruz and De Smedt are not alone in answering "no," or at least "not easily." It is no surprise that this is the unanimous answer among theistic apologists. But it is somewhat surprising how popular this answer is among agnostic (and even some atheist) scientists. Although there are several notable exceptions, several of which we have reviewed in earlier chapters, most csR scholars seem hesitant to draw any explicit conclusions about the actual existence of the gods (or God) conceived in the human minds they study.

As the theoretical integration of biological and cultural factors continues to gain momentum, new light is being shed on the way in which religious beliefs, attitudes and practices rely on and reinforce anxiety about in-group cohesion. This is one reason I prefer to refer to the multi-disciplinary "field" in which 
most of these scholars work (or at least sometimes play) as the bio-cultural study of religion. Finding defeaters for religion may not exactly be "straightforward," but if we pause to ask for directions - to reflect on the inferential directionality of our argumentation - it becomes relatively easy to spot theistic bunk.

\section{Step 1. Leave the Cul-de-sac of Deductive/Inductive Arguments}

Like most scholars on either side of (or on the fence in) the debate over the rationality of theism, De Cruz and De Smedt focus almost entirely on arguments that rely on inductive or deductive modes of inference. In other words, their discussions of the existence of God center around two sorts of question: whether it can be proven by valid reasoning from appropriate premises, and whether it can be rendered probable based on the evaluation of appropriate evidence. This is evident, for example, in their analysis of the "two types of possible defeaters" of theism, namely, those that rebut and those that undercut religious belief. "A rebutting defeater gives us reason to think the conclusion must be false. By contrast, an undercutting defeater does not challenge the conclusion directly, but makes us doubt that the evidence supports the hypothesis" (183).

The important thing to notice here is the (only?) two possible sorts of defeaters the authors treat rely on deduction or induction, eclipsing abduction and retroduction (to which I will return below). A rebutting defeater relies primarily on deductive inference. De Cruz and De Smedt do not think this sort of defeater works because theists and atheists disagree on the premises. "One's prior assumptions about the existence of God mediate to an important extent the perceived reliability of cognitive faculties that are involved in the formulation of natural theological arguments - this holds for both debunkers and vindicators" (198, emphasis added). As a side note, I should point out that this seems inconsistent with their claim elsewhere that "natural theology, unlike most other forms of theology, does not explicitly presuppose the existence of God ....(and) should be intelligible regardless of one's metaphysical assumptions by appealing to observations and intuitions shared by all" (11). The more important point here, however, is the one on which we agree: focusing on deductive arguments gets us nowhere.

An undercutting defeater relies on induction, challenging some aspect of the evidence that theists offer in their attempts to lend credibility to belief in God. This is especially prevalent in the discussion around teleological arguments. At the end of their chapter on the argument from design, the authors insist that claims about theistic evolution (for example) cannot be evaluated 
purely by the empirical evidence. The rationality of the design argument "relies on the prior probability one places on the existence of God.... The reason why some find the design argument compelling and others do not lies not in any intrinsic differences in assessing design in nature but rather in the prior probability they assign to complexity being produced by chance events or by a creator" (84, emphases added). I think the differences in assessing design are also shaped by the extent to which a person has contested the evolved disposition toward guessing "an idiosyncratic hidden agent interested in my in-group" when confronted with ambiguous phenomena, but at this stage I want to emphasize my agreement: focusing on inductive arguments gets us nowhere.

Apologists and atheists have driven around in circles in this inferential culde-sac for centuries, and so it is no surprise the interlocutors keep meeting each other at the same old impasses. Despite its astonishing fecundity in so many other arenas of discourse, the "cognitive turn" in science (and philosophy) has not yet altered the course of (a)theological debate, which all too often follows the ruts carved out by the longstanding attempts to (dis)prove God through deduction or render God (im)probable through induction. It is time to explore other avenues. Yes, theists and atheists have quite different "prior assumptions" and "prior probabilities," but where did these come from? We cannot answer this question simply by appealing to the cognitive generation of the content of such (dis)belief. We must also ask about the coalitional contexts within which ideas about the gods (and God) are kept alive.

\section{Step 2. Start at the Site of Alleged Religious Abductions}

C.S. Peirce used the term abduction to refer to the way in which we develop conjectures that are intended to make sense of ambiguous phenomena. I observe a surprising fact $(\mathrm{C})$. But then I reflect - or intuit - that if $(\mathrm{A})$ were true, (C) would be a matter of course. This gives the hypothesis (A) an initial plausibility. In everyday life, we usually go with this "best guess" unless and until we encounter some challenge to it. In scholarly life, however, we are encouraged to overcome our confirmation bias, to reflect critically on our own idiosyncratic interpretations, and to invite others to challenge our hypotheses. Although abductive inferences may be based on earlier observations and utilized in later logical formalizations, they are not validated (as in induction) or proven (as in deduction); rather, they are rendered more or less theoretically plausible within a particular context in which they are evaluated as more or less pragmatically feasible. 
Religious ideas about animal-spirits, ancestor-ghosts or gods are not the result of deduction or induction, but of abduction. For example, a Christian does not think the Eucharistic wafer has turned into the body of the risen Christ because she has observed its transmutation multiple times, nor because she has deduced this conclusion from theologically correct premises about the hypostatic union of the two natures of Christ. Rather, she finds herself confronted by a highly ambiguous phenomenon, the "surprising fact" that everyone around her participating in this ritual seems to be detecting the (real) presence of a supernatural agent (C). If the ritual officer (priest) really belonged to a social category of persons who were divinely imbued with a special power $(\mathrm{A})$, then (C) would be a "matter of course." Hypotheses like (A) "work" in the sense that they hold together believers ritually engaged in religious sects. ${ }^{3}$

Ideas about counterintuitive supernatural agents are relatively immune to inductive challenges because they can live forever in the meta-representational limbo created by regular participation in causally opaque rituals; such "prior probabilities" can never be empirically falsified through observation. Godconcepts are also relatively immune to deductive challenges because the symbolic representational contexts of religious in-groups are so open-textured that an endless array of quasi-propositions can be generated to qualify and protect the "prior assumptions" within them. Abductive challenges, on the other hand, press those who think they have detected a mysterious contingently-embodied intentional force to reflect carefully on the way in which they might be unconsciously immunizing such hypotheses from serious critique because they have a conflict of interest in maintaining the idiosyncratic beliefs of their own religious coalition.

An emphasis on the importance of context biases as well as content biases for understanding the origin and development of religion was already present in many of the early founding texts of the bio-cultural study of religion, ${ }^{4}$ but as we saw in Chapter 1 above, it seems to have been intensifying in more recent literature. Extensive cross-cultural psychological experimentation and ethnographic research suggest that one of the main reasons that "punitive supernatural agent" (e.g., the son of a god who is "coming to judge the living and the dead") continues to feel like the "best guess" to people in religious contexts is that these sorts of agents function as "better guards." Shared belief that there

3 I discuss the importance of abductive (as well as retroductive) inferences for understanding the "phylogenetic fallacies" of theistic argumentation in more detail in Chapter 4 of Shults, Theology after the Birth of God.

4 See, e.g., Lawson and McCauley, Rethinking Religion; Boyer, The Naturalness of Religious Ideas. 
are invisible "watchers" who have the capacity and desire to reward or punish those who do not follow the norms of the in-group tends to increase cooperation within and commitment to religious coalitions.

In an earlier article on the epistemic status of scientific beliefs, De Cruz and De Smedt do emphasize the role that the context of a large scientific community plays in the acquisition of truth-approximating knowledge under a broad range of conditions. Using the Price equation to assess the effects of cultural transmission and cognitive biases in scientific progress, they show that even low fidelity of transmission and substantial cognitive bias can be offset "by the tendency to make many different scientific inferences and by a large scientific community." I would argue that this is partially due to the way in which academic contexts press individuals to reflect critically on the extent to which their hypotheses (abductive inferences) are open to critique from other individuals outside their own in-group (or research team) and might be surreptitiously shaped by conflict of interest.

In A Natural History of Natural Theology, the authors indirectly approach the issue of abduction when they discuss the way in which "inference to the best explanation" plays a role in arguments from design (64). My interest, however, is in the primal abductions about supernatural agents that have become deeply ingressed within a theist's interpretive scheme long before he or she gets around to dealing with abstract theological hypotheses about the best explanation for apparent design. It is precisely religious abductions of this sort - those that flow naturally from the evolved bias toward guessing that a hidden, person-like, coalition-favoring force is the cause of ambiguous phenomena - that scientific and philosophical training encourages one to challenge. Supernatural agent abductions are not simply prior "assumptions" or "probabilities," but biased hypotheses powerfully protected from critique by ongoing participation in the shared imaginative engagement of a particular religious coalition, wherein one is constantly required to send credible and costly signals of commitment to other in-group members.

How do scientists, (non-religious) philosophers, and most educated people in general, respond when they hear claims about UFO abductions, the detection of spirit-guides at a séance, celestial forces fulfilling astrological predictions, or the presence of trolls in the Norwegian forest? They consider them bunk. It is not always clear why "gods" are given a pass. De Cruz and De Smedt devote considerable time to "Reformed" epistemology, without asking why this should be given more credence than "Lutheran," "Mormon" or "Hindu"

5 De Cruz and De Smedt, "Evolved Cognitive Biases and the Epistemic Status of Scientific Beliefs," Philosophical Studies 157, no. 3 (2012): 427. 
epistemology. Alvin Plantinga claims that Christians have access to more evidence than naturalists (and members of other out-groups) because of their special experience of divine revelation, ${ }^{6}$ and Justin Barrett appeals to the biblical myth of the "fall" of Adam and Eve in his explanation of the failure of nonbelievers to detect God. ${ }^{7}$ Normally this sort of special pleading would never be allowed to stand in serious, academic discourse.

Appealing to the noetic effects of sin, or some other flaw appraised by a punitive supernatural agent, to discredit the hypotheses of one's opponents, is surely one of the most appalling of noetic sins, and yet most scholars in the bio-cultural study of religion just let such claims slide. Why? The response "because these claims occur in the context of religious and theological discourse, which deals with spiritual realities beyond the boundaries of science" simply begs the question: why would anyone think that spiritual forces are real in the first place? The scientific study of religion has provided a really good answer to this question: such hypotheses are the result of abductive inferences covertly guided by implicit cognitive and coalitional biases. At the end of their book, De Cruz and De Smedt suggest that "one of the challenges for the metaphysical naturalistic worldview is to explain why such beliefs are widespread if their referents (supernatural entities) do not exist" (198). In light of the bio-cultural study of religion, it is not at all challenging to explain why beliefs in UFO abductions are widespread although their referents (probing aliens) do not exist. Why hesitate to make similar claims about gods (or God)?

\section{Step 3. Don't be Afraid to Pursue Retroductive Destinations}

"Retroduction," a term also introduced by Peirce, refers to inferences that lead to claims about what makes a phenomenon possible or, better, the conditions for its actualization. Like abduction, it involves the formulation of hypotheses, but retroductive conjectures are about the conditions without which a phenomenon could not be (or become) as it is. They "lead back" (retro-ducere) from more or less plausible and stable abductions to that which determines the existence of the phenomenon itself. Now, scientists make retroductive

6 Plantinga, "Games Scientists Play," in The Believing Primate: Scientific, Philosophical and Theological Reflections on the Origin of Religion, ed. Schloss and Murray (Oxford University Press, 2009), 167.

7 Barrett, "Cognitive Science, Religion, and Theology," in The Believing Primate: Scientific, Philosophical and Theological Essays on the Origin of Religion, ed. Schloss and Murray (New York: Oxford University Press, 2009), 97-98. 
inferences all the time. They have no difficulty claiming that bodies, brains, ritual behaviors, cultural artifacts, etc., all exist and have varying conditioning effects upon one another.

Yet, when it comes to supernatural agents, many go out of their way to emphasize that CSR has no bearing whatsoever on their existence. Perhaps this is due, in part, to the constant reminders they hear from theists that one cannot "prove" a negative like "God does not exist" (a discussion of reductio ad absurdum arguments is beyond the scope of this essay). As should be clear by now, however, I am not interested here in proof (or probability), but in plausibility. In fact, scientists quite often deny the existence of something in their hypothesizing about causal relations. Most physicians in the 18th century believed in the existence of humours in the blood and other bodily fluids that affected human temperament and disease. Most physicists in the 19th century believed in the existence of ether, an unseen medium through which light allegedly travelled. Today, scholars in these fields have no qualms about claiming that ether and humours do not exist.

To take an example more directly relevant to the bio-cultural study of religion, Paul Bloom devotes most of his book Descartes' Baby to explaining the evolved mechanisms that generate conceptions of "immaterial" entities like a "soul" that can be separated from a "body," biases that so easily mislead children (and adults) into accepting Cartesian dualism. Bloom explicitly claims: "Descartes was mistaken ... We do not have immaterial souls." ${ }^{8}$ However, he concludes by reassuring religious people that all of this is "logically separate from the question of whether God exists." ${ }^{\prime 9} \mathrm{He}$ has no problem retroductively inferring that there is no Cartesian "ghost" in the machine. Why, then, the reticence to straightforwardly reject hypotheses that appeal to the "Holy Ghost" in the hearts of Christian believers or "ancestor-ghosts" in the heart of the forest?

Like virtually all other scientists and (non-religious) philosophers, De Cruz and De Smedt explicitly accept methodological naturalism. "Thus when investigating the cognitive basis of intuitions in natural theology, we will not adopt metaphysical naturalism, which holds that there are not supernatural entities, nor will we assume a metaphysical theism, which takes the existence of God as a given. Moderate naturalism is neutral with respect to metaphysical assumptions" (59, emphasis added). It is certainly methodologically virtuous not to "assume" that something (say, a UFO, a troll or a god) does not exist, but moderate naturalism quite naturally leads to moderated metaphysical (retroductive)

8 Bloom, Descartes' Baby: How the Science of Child Development Explains What Makes Us Human, (New York: Basic Books, 2005), xii.

9 Ibid., 216. 
claims about the existential conditions of causally complex phenomena - as illustrated throughout A Natural History of Natural Theology.

Still, one might be tempted to simply leave (apologetic) theologians and philosophers of religion to their imaginative engagement with supernatural agents, and get on with the work of critiquing and constructing scientific hypotheses. It is certainly not the job of scientists qua scientists to address the theoretical and practical problems associated with religiously-salient biases. But scientists are human too, and I see know reason why they should feel compelled not to point out the maladaptive effects that theism has on our species when it comes to (for example) dealing with the challenges of climate change and the injustices of consumer capitalism. The cognitive and coalitional biases that reproduce religion were naturally selected in the upper Paleolithic because these traits granted survival advantage to individuals in groups where they were widely distributed in the population.

In the complex, large-scale, pluralistic societies in which most of us live, however, these biases are no longer adaptive - at least if our concern is with the (temporal) adaptation of the race as a whole, as well as other sentient species, and not simply with the (eternal) survival of a particular religious in-group. The problem is that the cognitive biases that generate superstitious interpretations of nature and the coalitional biases that exacerbate segregative inscriptions of society are reciprocally reinforcing. As we saw in Chapter 1, priming people to think about supernatural agents can activate anxiety about out-groups, and participating in religious rituals can enhance credulity toward supernatural authorities. Theism, which follows out the hyper-sensitive tendency to detect supernatural agents to infinity and presses the hyper-sensitive tendency to protect supernatural coalitions to eternity, intensifies the psychological, political, and philosophical problems associated with religious belief and behavior.

Can theism be defeated? There is really no need to try and "defeat" it. If the plausibility of naturalistic explanations of causal forces in the cosmos and the feasibility of secularist inscriptions of society in pluralistic contexts continue to capture the imagination of new generations of Homo sapiens, then theism, like every other form of bias that loses its ritual hold on young minds, may just slowly fade away into cultural irrelevance.

In their response to my original commentary in Religion, Brain \& Behavior, De Cruz and De Smedt said that they disagreed "with the claim that natural theological arguments are mainly written with the aim of signaling commitment to in-group members." As evidence against this claim (a claim which I did not make), De Cruz and De Smedt point out that "many natural theological arguments are formulated in a context of intellectual diversity, in particular 
one where naturalistic worldviews are on the rise... [and can be seen] as a countermovement to the rising influence of naturalism in philosophy and everyday life."10

The way in which they phrase this claim, as well as the evidence they offer to refute it, betrays a misunderstanding of costly signaling theories of religion. Costly signals are not something one "aims" to send. They are sent automatically and somewhat unconsciously as deliverances of the theistic credulity and conformity biases described above. Moreover, one would expect costly signals of the theological type to be sent in exactly the sort of context De Cruz and De Smedt describe: pluralistic environments in which the religious worldview of one's in-group is being robustly challenged. ${ }^{11}$ Signals of one's commitment to theism through costly scholarship are (unconsciously) directed not toward one's unbelieving opponents, but toward the religious in-group crowd watching the match.

Theoretical analyses of literature in the philosophy of religion and empirical research on philosophers of religion have led to increasingly serious warnings about the pervasive theistic biases that permeate this academic discipline. ${ }^{12}$ In the last few years, several scholars have argued that empirical findings and theoretical developments in the cognitive science of religion have provided powerful debunking arguments against religious beliefs. ${ }^{13}$ This has elicited a

10 De Cruz and De Smedt, "Naturalizing Natural Theology," Religion, Brain \& Behavior, 6, no. 4 (2015): 22.

11 Mahoney, "The Evolutionary Psychology of Theology," in The Attraction of Religion: A New Evolutionary Psychology of Religion, ed. Slone and van Slyke (London: Bloomsbury Academic, 2015).

12 See, e.g., Tobia, "Does Religious Belief Infect Philosophical Analysis?" Religion, Brain \& Behavior 6, no. 1 (2016); Draper and Nichols, "Diagnosing Bias in Philosophy of Religion." The Monist 96, no. 3 (2013): 420; Nola, "Do Naturalistic Explanations of Religious Beliefs Debunk Religion?" in A New Science of Religion, ed. Dawes and Maclaurin (London: Routledge, 2003).

13 Wilkins et al., "Evolutionary Debunking Arguments in Three Domains" in A New Science of Religion, ed. Dawes and Maclaurin (London: Routledge, 2013) Griffiths and Wilkins, "Crossing the Milvian Bridge: When Do Evolutionary Explanations of Belief Debunk Belief?" in Darwin in the Twenty-First Century: Nature, Humanity, God, ed. Sloan et al., (Notre Dame, IL: University of Notre Dame Press, 2015); Teehan, "The Cognitive Bases of the Problem of evil," The Monist 96, no. 3 (2013): 325; Teehan, "Cognitive Science and the Limits of Theology," in The Roots of Religion: Exploring the Cognitive Science of Religion, ed. Trigg and Barrett (Surrey, uK: Ashgate, 2014); Schaffer, "Cognitive Science and Metaphysics: Partners in Debunking," in Goldman and His Critics, ed. Korblith and Maclaughlin (New York: Wiley-Blackwell, 2016); van Eyghen, "Two Types of 'Explaining Away' Arguments in the Cognitive Science of Religion," Zygon 51, no. 4 (2016). 
host of responses from apologetic (or agnostic) philosophers, eager to point out that none of this entails that religious beliefs are false, and that CSR alone is insufficient as a defeater of theism. ${ }^{14}$ However, I have argued that focusing on entailment relations is a red herring. By definition, negative logical assertions cannot be proven; no set of premises will ever entail that gods and ghosts (or unicorns for that matter) do not exist. The more relevant question is whether belief in such beings is plausible.

Moreover, as we have seen in earlier chapters, CSR is not in fact alone. While this discipline focuses on explaining the evolved mechanisms that shape belief, controlled experimental designs in several other disciplines have demonstrated the way in which manipulating religious beliefs increases errors and misattributions. CSR itself may not be able to comment on the ultimate reliability of religious beliefs, but

experimental psychology has a great deal of evidence supporting their unreliablity and malleability... Not only is it impossible to prove a negative, these types of arguments also ignore abductive standards of evidence, which prefer the most likely explanation for a phenomenon while requiring the fewest additional assumptions ... [CSR] must be viewed in the light of findings from experimental psychology indicating that religious and spiritual intuitions are unreliable in shaping beliefs (e.g., the over-detection of animacy), and that rational processes [used to defend them] likewise represent motivated biases. A range of processes occurring at multiple levels (neural, cognitive, personality, social) have been shown by experimentation to produce misattributed Rs [religious/spiritual] thoughts and experiences indistinguishable from spontaneous or "genuine" ones. This has relevance to meta-physical claims because it indicates that these experiences, often refered to as sui generis or evidential of the supernatural can be accounted for by naturalistic mechanisms, thus constituting "false positives."15

14 Leech and Visala, "The Cognitive Science of Religion: A Modified Theist Response," Religious Studies 47, no. 3 (2011); Johnson, et al., "The Elephant in the Room: Do Evolutionary Accounts of Religion Entail the Falsity of Religious Belief?" Philosophy, Theology and the Sciences 1, no. 2 (2014); Barrett and Trigg, "Cognitive and Evolutionary Studies of Religion," in The Roots of Religion: Exploring the Cognitive Science of Religion, ed. Trigg and Barrett (Surrey, u K: Ashgate, 2014); Visala, Naturalism, Theism and the Cognitive Study of Religion: Religion Explained? (Routledge, 2016).

15 Galen, "Overlapping Mental Magisteria: Implications of Experimental Psychology for a Theory of Religious Belief as Misattribution," Method and Theory in the Study of Religion, 29, no. 3 (2017), 27, 33 . 
All of the scientific disciplines that contribute to the bio-cultural study of religion facilitate the debunking of theism. Naturally, quite naturally, theistic biases will continue to shape the reactions to (and perceptions of) this research among individuals for whom engaging in religious sects has become a central part of their narrative identity and a primal source of meaning for those they love.

This applies to laypeople and scholars alike. Attacking specific religious beliefs directly through arguments involving proof and probability can all too easily make things worse, amplifying precisely those biases that are blocking the embrace of a robust naturalist and secularist worldview in the first place. This is why I recommend the strategy of (more or less gently) continuing to point out the role that evolved content and context biases play in engendering and nurturing their conceptions of the idiosyncratic supernatural agents imaginatively engaged in the rituals of their in-group.

But it is important to remember that science is not the only anaphrodisiac when it comes to religious sects. Insofar as it promotes analytical and critical reflection, philosophy can also jolt people out of the mood. To reiterate, I am not suggesting that atheist philosophers (or unbelievers in general) are not biased. There is no doubt that some non-religious folks struggle with sexism, classism, racism, and other biases. By (my) definition, however, an atheist has learned, or is in the process of learning, how to overcome the credulity and conformity biases associated with theism (or, through some combination of personality and contextual factors, never came under the seductive influence of these biases in the first place). Insofar as theism bolsters sexism, classism, and racism (at least at the population level), those concerned about the latter ought to embrace the task of undermining the former. Godless philosophy can help. In my view, the philosophical resources found in the work of Gilles Deleuze are among the most useful for fostering an adaptive atheism. 